\title{
Hippocampal and perirhinal functions in recognition memory
}

\section{Malcolm W. Brown.}

I would like to correct a statement that was made by $\underline{\text { Squire }}$ et al. in a recent Review of recognition memory ${ }^{1}$. On page 879 , the Review ${ }^{1}$ states that 'In one study in monkeys ${ }^{72}, 34 \%$ of hippocampal cells responded differently depending on whether the stimulus was familiar or novel.' Reference 72 is a paper by Wilson et al. ${ }^{2}$ : their figure for the number of neurons that respond differently to novel stimuli (that is, stimuli that have never previously been presented or stimuli that have not been seen for many days) presented for the first time than to familiar stimuli (stimuli being shown for the second time in a brief period) is zero out of $>650$ neurons recorded in the hippocampus and subicular cortex - that is, $0 \%$ (see REF. 2 , page 315).

The figure of $34 \%$ actually refers to repeated presentations of familiar stimuli in a delayed matching-to-sample task (DMS task; see REF. 2, page 319). It is important to understand that these familiar stimuli are repeated frequently within short time periods and that the response difference being referred to is that between stimuli being presented for the second time on match trials and stimuli being presented for the second time on non-match trials. Before such response differences between match and non-match trials can be accepted as providing a substrate for general, long-term familiarity discrimination, evidence must be given that they satisfy the appropriate criteria. The delay interval between the first and second stimulus presentations in the experiments referred to was 0.5 seconds - well within the time range of short-term memory or attentive mechanisms. Such match-mismatch differences have not been demonstrated across time delays appropriate to long-term memory, when so many items must be retained that they are outside the capacity of short-term memory, and when the delay intervals are filled with distraction. Other references ${ }^{3,4,5}$ cited in the Review ${ }^{1}$ also do not provide such evidence.

Indeed, Wilson et al. ${ }^{2}$ provided evidence that the match-mismatch differences do not provide a possible general substrate for longterm familiarity discrimination and are not related to novelty detection: referring to 395 hippocampal neurons recorded in a serialrecognition task, they state (on page 318 ) that, "For none of these units were consistent differences found between trials on which novel stimuli were presented and those on which the stimuli reappeared as familiar. An additional $>250$ units tested with objects and in the DMS task for stimuli varying in their novelty/familiarity did not show consistent responses dependent on the novelty/familiarity of the stimuli." Crucially, agreeing with these findings, Riches et al. ${ }^{6}$ further confirmed that when novel stimuli were introduced into such a delayed matching-to-sample task, the responses of hippocampal neurons did not differentiate between stimuli that were novel and stimuli that were highly familiar. Hence, it is possible to dissociate responses to novelty from those to repeated familiar stimuli on match or mismatch trials in a delayed matchingto-sample task.

This situation contrasts with findings for the perirhinal and adjacent cortex. Here, the responses of up to $25 \%$ of the neurons are reduced when initially novel stimuli are seen for a second time, regardless of whether the stimuli are presented in a delayed matchingto-sample task or in other situations ${ }^{2,6-12}$. Such response reductions have been shown to occur when the time delay between presentations is long ( 24 hours in many cases), when the delay interval is filled with distractions, and when the number of items needing to be held in the memory is well over the capacity of short-term memory ${ }^{6,8,12-14}$. Accordingly, such response reductions do satisfy the criteria of general long-term familiarity discrimination.

By contrast, when more complex discriminations of prior occurrence are required, particularly when subjects are taught to encode spatial information, hippocampal neurons are often involved (for example, in monkeys ${ }^{15}$, rats $^{5,16}$ and humans $\left.{ }^{17}\right)$. It is unsurprising that the perirhinal cortex and the hippocampus work cooperatively when it is appropriate - this does not prevent their different functions from being dissociated under other circumstances ${ }^{2,6,12-14,16}$.

University of Bristol, MRC Centre for Synaptic Plasticity, Department of Anatomy, School of Medical Sciences, Bristol, BS8 1TD, UK.

e-mail:M.W.Brown@bristol.ac.uk

doi: 10.1038/nrn2154-c1

Published online 2 April 2008

Squire, L. R., Wixted, J. T. \& Clark, R. E. Recognition memory and the medial temporal lobe: a new perspective. Nature Rev. Neurosci. 8, 872-883 (2007) Wilson, F. A. W., Brown, M. W. \& Riches, I. P. in Cellular Mechanisms of Conditioning and Behavioral Plasticity (eds Woody, C. D. Alkon, D. L. \& McGaugh, J. L.) 313-328 (Plenum, New York, 1988).

3. Otto, T. \& Eichenbaum, H. Neuronal activity in the hippocampus during delayed non-match to sample performance in rats: evidence for hippocampal processing in recognition memory. Hippocampus 2 323-334 (1992)

4. Suzuki, W. A. \& Eichenbaum, H. The neurophysiology of memory. Ann. NY Acad. Sci. 911, 175-191 (2000). Wood, E. R., Dudchenko, P. A. \& Eichenbaum, H. The global record of memory in hippocampal neuronal activity. Nature 397, 613-616 (1999).

6. Riches, I. P., Wilson, F. A. W. \& Brown, M. W. The effects of visual stimulation and memory on neurons of the hippocampal formation and the neighboring parahippocampal gyrus and inferior temporal cortex of the primate. J. Neurosci. 11, 1763-1779 (1991). Brown, M. W., Wilson, F. A. W. \& Riches, I. P. Neuronal evidence that inferomedial temporal cortex is more important than hippocampus in certain processes underlying recognition memory. Brain Res. 409, 158-162 (1987)

8. Fahy, F. L., Riches, I. P. \& Brown, M. W. Neuronal activity related to visual recognition memory: longterm memory and the encoding of recency and familiarity information in the primate anterior and medial inferior temporal and rhinal cortex. Exp. Brain Res. 96, 457-472 (1993).

9. Li, L., Miller, E. K. \& Desimone, R. The representation of stimulus familiarity in anterior inferior temporal cortex. J. Neurophysiol. 69, 1918-1929 (1993).

10. Miller, E. K., Li, L. \& Desimone, R. Activity of neurons in anterior inferior temporal cortex during a shortterm memory task. J. Neurosci. 13, 1460-1478 (1993).

11. Sobotka, S. \& Ringo, J. L. Investigation of long-term recognition and association memory in unit responses from inferotemporal cortex. Exp. Brain Res. 96, 28-38 (1993).

12. Xiang, J. Z. \& Brown, M. W. Differential neuronal encoding of novelty, familiarity and recency in regions of the anterior temporal lobe. Neuropharmacology 37, 657-676 (1998).

13. Brown, M. W. \& Aggleton, J. P. Recognition memory: what are the roles of the perirhinal cortex and hippocampus? Nature Rev. Neurosci. 2, 51-61 (2001)

14. Brown, M. W. \& Xiang, J. Z. Recognition memory: neuronal substrates of the judgement of prior occurrence. Prog. Neurobiol. 55, 149-189 (1998).

15. Rolls, E. T. et al. Hippocampal neurons in the monkey with activity related to the place in which a stimulus is shown. J. Neurosci. 9, 1835-1845 (1989).

16. Wan, H., Aggleton, J. P. \& Brown, M. W. Different contributions of the hippocampus and perirhinal cortex to recognition memory. J. Neurosci. 19, 1142-1148 (1999).

17. Rutishauser, U., Namelak, A. N. \& Schuman, E. M. Single-trial learning of novel stimuli by individual neurons of the human hippocampus-amygdala complex. Neuron 49, 805-813 (2006). 